\section{Chaikovskaya E.}

\title{
COMPLEX MATHEMATICAL MODELING OF HEAT PUMP POWER SUPPLY BASED ON WIND-SOLAR NETWORK ELECTRICAL SYSTEM
}

The object of research is to support the functioning of a heat pump power supply based on a grid-type windsolar electric system using hybrid solar collectors.

One of the most problematic areas is the harmonization of energy production and consumption in the context of distributed energy generation using renewable sources. Connecting to Smart Grid technologies will prevent the peak load of the power system in conditions of voltage regulation when connecting the heat pump power supply.

An integrated system has been developed to support the operation of heat pump power supply based on predicting changes in the temperature of local water when measuring voltage from hybrid solar collectors at the input to the grid inverter, voltage at the output of the frequency converter and voltage frequency. The adoption of advanced decisions to maintain the temperature of local water by changing the power of the electric motor of the heat pump compressor is based on establishing the ratio of the voltage at the input to the grid inverter and the voltage at the output of the frequency converter are measured. The change in the refrigerant flow rate according to the frequency control of the electric motor of the heat pump compressor occurs in accordance with the change in the thermal power of the low-potential energy source - the lower section of the two-section storage tank connected to hybrid solar collectors. The architecture, the mathematical substantiation of the architecture of the technological system, the mathematical substantiation of supporting the functioning of the heat pump power supply are proposed. The basis of the technological system is a dynamic subsystem, which includes the following components: wind power plants, photovoltaic solar panels, hybrid solar collectors, grid inverter, two-section storage tank, heat pump, frequency converter. The operating parameters of the heat pump system, the parameters of heat exchange in the condenser of the heat pump, the time constants and coefficients of the mathematical model of the dynamics of the temperature of local water for the established levels of functioning are determined according to the coordination of production and consumption of energy.

Keywords: wind-solar power system, photovoltaic solar panels, hybrid solar collectors, heat pump, grid inverter.

\section{Introduction}

Distributed generation of electricity using renewable sources requires intelligent systems for managing electricity flows and consumption [1, 2]. Smart Grid technologies, demand management systems and energy storage are new components for the integration of distributed energy generation in the energy system. So, in work [3], it is proposed to control the consumption of electrical energy by exchanging information in real time. The work [4] is devoted to the introduction of stochastic optimization of distributed generation of electrical energy using fuzzy logic. In [5], a cyberphysical control system for distributed generation of electrical energy, based on the theory of a consensus protocol, is proposed. In [6], an intelligent converter for voltage regulation by absorbing or supplying reactive power is proposed. In [7], a model for prioritizing sensitivity to changes in data is presented, based on accurate measurement of electrical energy consumption. In terms of connection to intelligent control systems in [8], it is proposed to predict voltage changes when measuring the temperature of the electrolyte in the volume of batteries. An energysaving technology has been developed for the operation of a storage battery; it does not allow overcharging, but it does not allow discharge based on the coordination of electrochemical and diffusion processes of discharge and charge. The work [9] is devoted to forecasting changes in parameters for connecting to Smart Grid technologies, which presents an integrated system for supporting the functioning of a wind-solar electric system based on predicting changes in battery capacity. The voltage is measured at the input to the hybrid charge controller and at the output from the inverter. The adoption of advanced decisions to change the power of the thermoelectric accumulator is based on establishing the ratio of the voltage at the input to the hybrid charge controller and at the output from the inverter when measuring the voltage frequency. The change in the flow rate and temperature of the heated water is provided, reducing the charge period to $30 \%$, based on the change in the number of revolutions of the circulation pump electric motor.

An urgent further development in this direction is the complex mathematical modeling of heat pump power supply for predicting changes in the temperature of local water as part of a network wind-solar electric system using hybrid solar collectors. 


\section{The object of research and its technological audit}

The object of research is to support the functioning of a heat pump power supply based on a grid-type windsolar electric system using hybrid solar collectors. The network wind-solar electric system with a capacity of $10 \mathrm{~kW}$ includes the following components:

- wind power plant of EUROWIND2 type (Ukraine);

- photovoltaic solar panels and hybrid solar panels ATMOSFERA-F2PV (Ukraine).

The heat pump system - Commotherm hybrid tower WW, Split DeLuxe (Austria) with a heating capacity of $5.7 \mathrm{~kW}$ is equipped with a two-section storage tank, the lower section of which has a volume of 200 liters, used as a low-potential energy source connected to hybrid solar collectors. The following levels of operation of the heat pump system have been established for the change in the temperature of the refrigerant at the inlet to the condenser and at the outlet from the condenser:

- first level: $45-40.5{ }^{\circ} \mathrm{C}$;

- second level: $50-45.5{ }^{\circ} \mathrm{C}$;

- third level: $55-50.5{ }^{\circ} \mathrm{C}$;

- fourth level: $60-55.5{ }^{\circ} \mathrm{C}$.

They correspond to changes in the temperature of local water: $35-40{ }^{\circ} \mathrm{C} ; 40-45{ }^{\circ} \mathrm{C} ; 45-50{ }^{\circ} \mathrm{C} ; 50-55{ }^{\circ} \mathrm{C}$.

The temperature of the low-potential energy source ethylene glycol solution at the outlet of the heat pump evaporator is: $16.3{ }^{\circ} \mathrm{C}, 12.3{ }^{\circ} \mathrm{C}, 8.6{ }^{\circ} \mathrm{C}, 4.9{ }^{\circ} \mathrm{C}$, corresponding to the established operating levels for heating up to a temperature of $20{ }^{\circ} \mathrm{C}$.

One of the most problematic areas is the harmonization of energy production and consumption in the context of distributed energy generation using renewable sources. Connecting to Smart Grid technologies will prevent the peak load of the power system in conditions of voltage regulation when connecting the heat pump power supply.

\section{The aim and objectives of research}

The aim of research is a comprehensive mathematical modeling of heat pump power supply as part of a network wind-solar electric system using hybrid solar collectors.

To achieve this aim, it is necessary to complete the following objectives:

1. To develop the architecture of the technological system and the mathematical substantiation of the architecture, the basis of which is an integrated dynamic subsystem.

2. To develop a mathematical justification for supporting the functioning of the heat pump power supply on the basis of making advanced decisions to change the power of the heat pump compressor electric motor to maintain the local water temperature.

3. To develop an integrated system for supporting the change in the temperature of local water based on frequency control of the heat pump power supply as part of the network wind-solar electric system.

\section{Research of existing solutions of the problem}

Known methods for improving heat pump systems based on a static level of research - economic, exergy, thermoeconomics - complicate the operation of heat pump systems due to the impossibility of coordinating production and consumption. Thus, in [10], on the basis of a comparative analysis of the energy and exergy methods, preference was given to the exergy method. The influence of the refrigerant consumption on the compressor capacity is estimated. And in [11], mathematical modeling of the components of the heat pump system was carried out for the purpose of complex modeling, but without the possibility of using it under operating conditions. In this work, let's start using a dynamic approach to mathematical modeling, but only with the aim of stabilizing control systems. The work [12] is devoted to a dynamic approach to optimization of heat pump systems. The influence of intensification of heat transfer on the performance of the heat pump system was established, but using mathematical models with lumped parameters. Evaluation of changes in parameters only in time does not provide a qualitative assessment of changes in the parameters of the technological process In order to reduce the service life of the external electrical network for the functioning of heat pump systems, the authors propose connections, for example, of solar panels [13]. This paper also presents a static level study on the effect of changing solar radiation in support of compressor capacity. In [14], a technological scheme of heat pump power supply for the use of a heat pump heater from a solar engine is proposed. The possibility of raising the compressor suction pressure and increasing the efficiency of the heat pump system using energy and exergy methods, but also at a static level, has been determined. Known, in addition to static models, and such [15], aiming to control heat pump systems using intelligent networks, but the tools proposed in this work require measuring the process parameters. This approach can't be used to make proactive decisions to support the operation of heat pump systems. Thus, work [16] presents an integrated Smart Grid system based on predicting changes in the power factor of a cogeneration system using heat pump power supply to a biogas plant, a low-potential energy source for which fermented wort. It is proposed to measure the voltage at the input to the inverter, at the output from the inverter and to estimate their ratio when measuring the voltage frequency. The adoption of advanced decisions to change the power of the heat pump and the number of heat exchanger plates of the engine cooling circuit allows maintaining the voltage at the inlet to the inverter and the temperature of the heated water.

There are various sources of low-grade energy for use in heat pump power supply. So, outside air, as a low-potential source of energy, is quite accessible, but the change in air temperature makes it difficult to maintain the functioning of heat pump systems [17]. Ground-to-water heat pumps are the most common, but their use should not interfere with the natural relaxation of the soil during unheated periods. Moreover, such systems require the construction of special ground heat exchangers for heating the brine supplied to the heat pump evaporator [18]. For example, the work [19] is devoted to the intensification of the heat exchange process, in which a specially developed spiral heat exchanger is presented and the optimal design parameters are established: length and diameter.

In this direction, a promising further development is the integrated modeling of heat pump power supply as part of a network wind-solar electric system using hybrid solar collectors to charge a low-potential energy source - 
the lower section of a two-section storage tank. The use of hybrid solar collectors for low-grade energy sources based on the lower section of the storage tank requires coordination of the functioning of dynamic systems: a low-grade energy source - an evaporator, an evaporator-compressor, a compressor-condenser based on predicting changes in the temperature of local water. Thus, in [20], an integrated system for supporting the functioning of heat pump power supply was developed based on predicting changes in the temperature of local water. This system is based on measuring the temperature of the refrigerant at the outlet of the condenser in relation to the measured evaporation pressure, which are part of the analytical definitions of the refrigerant flow rate and the number of revolutions of the compressor motor. But for these conditions, it is necessary to ensure the establishment of the ratio of the voltage at the input to the grid inverter from hybrid solar collectors to the voltage at the output from the frequency converter when measuring the voltage frequency. This will give the ability to bias the temperature change in local water.

\section{Methods of research}

Using the methodological, mathematical and logical substantiation of the architecture of technological systems [16], the architecture and mathematical substantiation of the architecture (1) of the technological system of heat pump power supply of the grid wind-solar electric system are proposed.

$$
\begin{aligned}
& \operatorname{WSESHP}(\tau)= \\
& =\left\{\left[\begin{array}{l}
{[D S(\tau)(\operatorname{PIDS}(\tau)} \\
\left\langle x_{0}(\tau), x_{1}(\tau), x_{2}(\tau), f(\tau), K(\tau), y(\tau, z), d(\tau)\right\rangle, \\
Z(\tau), P I D S(\tau)), R(\tau),\left(P B_{i}(\tau)\right.
\end{array}\right]\right\},
\end{aligned}
$$

where $\operatorname{WSESHP}(\tau)$ - a grid-type wind-solar electric system using heat pump power supply; IDS $\tau$ - - integrated dynamic subsystem (wind turbine, photovoltaic solar panels, hybrid solar collectors, grid inverter, heat pump, two-section storage tank, lower section of two-section storage tank, frequency converter); $\operatorname{PIDS}(\tau), P B(\tau)$-properties of the components of the technological system; $\tau$ - time, $\mathrm{s} ; z$ - spatial coordinate of the condenser axis, coincides with the direction of the flow of motion of the medium, $\mathrm{m} ; x(\tau)$ - impacts (change in solar radiation, wind speed, change in consumption of electrical energy and heat); $f(\tau)$ - parameters that are measured (voltage at the input to the grid inverter from hybrid solar collectors, voltage at the output of the frequency converter, frequency voltages, evaporation pressure, condensation pressure); $K(\tau)-$ coefficients of mathematical description of the dynamics of local water temperature; $y(\tau, z)$ - output parameters (local water temperature); $d(\tau)$ - dynamic parameters of local water temperature change; $Z(\tau), R(\tau)$ - logical relations in $I D S(\tau)$, $\operatorname{WSESHP}(\tau)$, respectively. Indices: $i$ - the number of elements of the technological system; 0,1,2 - initial stationary mode, external, internal nature of impacts.

Using the methodological, mathematical and logical substantiation of supporting the functioning of energy systems [16], a mathematical substantiation of supporting the functioning of heat pump power supply (2) as part of a network wind-solar electric system using hybrid solar collectors is proposed.

$$
\begin{aligned}
& \operatorname{SFHPWSES}(\tau)= \\
& =\left\{\left[\begin{array}{l}
(D(P(\tau), M M(\tau, z), A I(\tau, z), C(\tau), L C(\tau) \\
\left\langle x_{0}(\tau), x_{1}(\tau), x_{2}(\tau), f(\tau), K(\tau), y(\tau, z), d(\tau), F I(\tau)\right\rangle, \\
L M D(\tau), M D(\tau), N C(\tau), S(\tau), L S(\tau) \\
\langle f(\tau), K(\tau), y(\tau), d(\tau), F I(\tau)\rangle \\
P(\tau))), R(\tau),\left(P_{i}(\tau)\left\langle x_{1}(\tau), f_{i}(\tau), K_{i}(\tau), y_{i}(\tau)\right\rangle\right),
\end{array}\right]\right\},
\end{aligned}
$$

where SFHPWSES $(\tau)$ - the support for the functioning of the heat pump power supply as part of the network wind-solar electric system; $D(\tau)$ - an integrated dynamic subsystem (wind power plant, photovoltaic solar panels, hybrid solar collectors, grid inverter, two-section storage tank for hot water supply and heating, heat pump system: the lower section of a two-section storage tank - an evaporator for using hybrid solar collectors for charge of a low-potential energy source; evaporator-compressor; compressor-condenser, frequency converter); $P(\tau)$ - properties of elements SFHPWSES( $\tau)$; $M M(\tau, z)$ - complex mathematical modeling of the dynamics of changes in local water temperature; $A I(\tau, z)$ - reference information for assessing changes in local water temperature; $C(\tau)$ - monitoring the performance of the integrated dynamic system; $M D(\tau)$ - making decisions on changing the power of the heat pump compressor electric motor; $S(\tau)$ - identification of the state of the heat pump system; $L C(\tau), L M D(\tau)$, $L S(\tau)$ - logical relations in $C(\tau), M D(\tau), S(\tau)$, respectively; $F I(\tau)$ - functional resulting information on decision making; $N C(\tau)$ - new conditions of functioning as a result of decision making; $x(\tau)$ - impacts (change in solar radiation, change in wind speed, change in consumption of electrical energy and heat); $f(\tau)$ - parameters that are measured (voltage at the input to the grid inverter from hybrid solar collectors, voltage at the output of the frequency converter, voltage frequency, evaporation pressure, condensation pressure); $K(\tau)$ - coefficients of the mathematical description of the dynamics of changes in the temperature of local water); $y(\tau, z)$ - output parameter: analytical assessment of changes in local water temperature; $d(\tau)$ - dynamic parameters of local water temperature change; $z$ - spatial coordinate of the condenser axis, coincides with the direction of the flow of motion of the medium, $\mathrm{m} ; \tau$ - time, s. Indices: $i$ - constituents SFHPWSES $(\tau)$ (charge block, discharge block, functional efficiency evaluation block); 0,1,2 - initial mode, external, internal nature of impacts.

Mathematical modeling of the dynamics of the local water temperature is proposed when measuring the voltage at the input to the grid inverter from hybrid solar collectors, at the output from the frequency converter and voltage frequency. The change in the temperature of local water both in time and along the coordinate of the condenser axis is estimated, which coincides with the direction of the flow of the medium. The transfer function along the channel «local water temperature - refrigerant consumption», which was obtained as a result of solving a system of nonlinear differential equations, is presented as follows:

$$
W_{t_{v}-G_{x 1}}=\frac{K_{u} K_{x} \varepsilon\left(1-L_{e}^{*}\right)}{\left(T_{w} S+1\right) \beta-1}\left(1-e^{-\gamma^{\xi}}\right),
$$

where

$$
K_{u}=\frac{I\left(U_{1}-U_{2}\right)}{\left(N_{e}\right)} ; \quad K_{x}=\frac{m\left(\theta_{0}-\sigma_{0}\right)}{G_{e 0}} ; \quad \varepsilon=\frac{\alpha_{e 0} h_{e 0}}{\alpha_{w 00} h_{w 0}} ;
$$




$$
\begin{aligned}
& L_{e}^{*}=\frac{1}{L_{e}+1} ; \quad L_{e}=\frac{G_{e} C_{e}}{\alpha_{e 0} h_{e 0}} ; \quad \varepsilon^{*}=\varepsilon\left(1-L_{e}^{*}\right) ; \\
& \gamma=\frac{\left(T_{w} S+1\right) \beta-1}{\beta} ; \quad \xi=\frac{z}{L_{w}} ; \quad T_{w}=\frac{g_{w} C_{w}}{\alpha_{w 0} h_{w 0}} ; \\
& \beta=T_{m} S+\varepsilon^{*}+1 ; \quad T_{m}=\frac{g_{m} C_{m}}{\alpha_{w 0} h_{w 0}},
\end{aligned}
$$

where $\mathrm{Ne}$ - the power of the wind-solar electric system, $\mathrm{kW}$; $I$ - current, $\mathrm{A} ; U_{1}, U_{2}$ - voltage at the input to the grid inverter and at the output from the frequency converter, respectively, $\mathrm{V}$; $\alpha$ - heat transfer coefficient in the condenser, $\mathrm{kW} /\left(\mathrm{m}^{2} \cdot \mathrm{K}\right)$; $C$ - specific heat capacity of the refrigerant, $\mathrm{kJ} /(\mathrm{kg} \cdot \mathrm{K}) ; G-$ refrigerant consumption, $\mathrm{kg} / \mathrm{s} ; g$ - specific gravity of heated water, $\mathrm{kg} / \mathrm{m} ; h$ - specific surface area of the condenser, $\mathrm{m}^{2} / \mathrm{g}$; $t_{w}, \theta, \sigma$ - temperature of heated water, distributing wall, refrigerant, $\mathrm{K} ; z$ - coordinate of the length of the condenser, coincides with the direction of the flow of movement of the medium, $\mathrm{m} ; T_{w}, T_{m}$ - time constants characterizing the thermal storage capacity of local water, metal, $s ; m-$ an indicator of the dependence of the heat transfer coefficient on the refrigerant consumption; 1 - time, s; $S$ - parameter of the Laplace transform; $S=\omega j ; \omega-$ frequency, $1 / \mathrm{s}$.

Indices: 0 - stationary output mode; 1 - input to the capacitor; $w$ - internal flow - local water; $m$ - metal wall; $e$ - external flow - refrigerant.

The transfer function includes the $K_{u}$ coefficient, which evaluates the voltage change at the input to the grid inverter and at the output of the frequency converter is measured by measuring the voltage frequency. The real part of the transfer function (3) in assessing the change in the temperature of local water is highlighted:

$$
O(\omega)=\frac{\left(L_{1} A_{1}\right)+\left(M_{1} B_{1}\right) K_{u} K_{x} \varepsilon\left(1-L_{e}^{*}\right)}{\left(A_{1}^{2}+B_{1}^{2}\right)} .
$$

The $K_{x}$ coefficient includes the dividing wall temperature $\theta$ :

$$
\theta=\left(\alpha_{w} \frac{\left(\sigma_{1}+\sigma_{2}\right)}{2}+A \frac{\left(t_{1}+t_{2}\right)}{2}\right) /\left(\alpha_{w}+A\right),
$$

where $\sigma_{1}, \sigma_{2}$ - temperature of the refrigerant at the inlet and outlet of the condenser, $\mathrm{K}$, respectively;

$$
A=\frac{1}{\left(\delta_{m} / \lambda_{m}+1 / \alpha_{e}\right)},
$$

where $\delta$ - the wall thickness of the condenser, $\mathrm{m} ; \alpha-$ heat transfer coefficient, $\mathrm{kW} /\left(\mathrm{m}^{2} \cdot \mathrm{K}\right) ; \lambda$ - thermal conductivity of the condenser wall metal, $\mathrm{kW} /(\mathrm{m} \cdot \mathrm{K}) ; t_{1}, t_{2}$ - temperature of local water at the inlet and outlet of the condenser, $\mathrm{K}$, respectively. Indexes: $e$ - external flow - refrigerant; $w-$ internal flow - local water.

To use the real part $O(\omega)$, the following coefficients are extracted:

$$
\begin{aligned}
& A_{1}=\varepsilon^{*}-T_{w} T_{m} \omega^{2} ; \\
& A_{2}=\varepsilon^{*}+1 ; \\
& B_{1}=T_{w} \varepsilon \omega+T_{w} \omega+T_{m} \omega ; \\
& B_{2}=T_{m} \omega ;
\end{aligned}
$$

$$
\begin{aligned}
& C_{1}=\frac{A_{1} A_{2}+B_{1} B_{2}}{A_{2}{ }^{2}+B_{2}{ }^{2}} ; \\
& D_{1}=\frac{A_{2} B_{1}-A_{1} B_{2}}{A_{2}{ }^{2}+B_{2}{ }^{2}} ; \\
& L_{1}=1-e^{-\zeta C_{1}} \cos \left(-\xi D_{1}\right) ; \\
& M_{1}=-e^{-\zeta C_{1}} \sin \left(-\xi D_{1}\right) .
\end{aligned}
$$

Using the integral of the transition from the frequency domain in the time domain, the change in the temperature of local water both in time and along the spatial coordinate of the condenser axis is determined as follows:

$$
t(\tau, z)=\frac{1}{2 \pi} \int_{0}^{\infty} O(\omega) \sin (\tau \omega / \omega) \mathrm{d} \omega .
$$

According to formulas (1)-(3), the results of complex mathematical modeling of heat pump power supply using hybrid solar collectors are presented (Tables 1-3).

Table 1

Dperating parameters of the heat pump system

\begin{tabular}{|l|c|c|c|c|c|c|c|}
\hline $\begin{array}{c}\text { Levels of } \\
\text { operation }\end{array}$ & $G_{x^{\prime}} \mathrm{kg} / \mathrm{s}$ & $N_{\theta^{\prime}} \mathrm{kW}$ & $N_{t \prime} \mathrm{kW}$ & $U, \mathrm{~V}$ & $f_{,} \mathrm{Hz}$ & $n, \mathrm{rpm}$ & $C O P$ \\
\hline first level & 0.0340 & 0.705 & 1.4 & 194.2 & 24.28 & 738.4 & 8.08 \\
\hline second level & 0.0350 & 0.923 & 2.9 & 254.3 & 31.78 & 953.4 & 6.17 \\
\hline third level & 0.0357 & 1.185 & 4.3 & 326.5 & 40.81 & 1224.3 & 4.80 \\
\hline fourth level & 0.0363 & 1.452 & 5.7 & 400 & 50 & 1500 & 3.92 \\
\hline
\end{tabular}

Note: $G_{x}-$ refrigerant consumption, $\mathrm{kg} / \mathrm{s} ; N_{e}-$ power of the compressor electric motor, $\mathrm{kW} ; N_{t}$ - thermal power of the low-grade energy source, $\mathrm{kW} ; U$ - voltage, $\mathrm{V} ; f$ - voltage frequency, $\mathrm{Hz} ; n-$ the number of revolutions of the compressor electric motor, rpm; COP - coefficient of performance of the heat pump system

Table 2

Heat transfer parameters as part of complex mathematical modeling

\begin{tabular}{|l|c|c|c|}
\hline \multirow{2}{*}{$\begin{array}{c}\text { Levels of } \\
\text { operation }\end{array}$} & \multicolumn{3}{|c|}{ Parameter } \\
\cline { 2 - 4 } & $\alpha_{e \prime} \mathrm{W} /\left(\mathrm{m}^{2} \cdot \mathrm{K}\right)$ & $\alpha_{\mathrm{w}} \mathrm{W} /\left(\mathrm{m}^{2} \cdot \mathrm{K}\right)$ & $k, \mathrm{~W} /\left(\mathrm{m}^{2} \cdot \mathrm{K}\right)$ \\
\hline first level & 1148.9 & 784.8 & 459.6 \\
\hline second level & 1192.7 & 901.2 & 505.2 \\
\hline third level & 1261.0 & 1075.9 & 570.2 \\
\hline fourth level & 1383.5 & 1371.7 & 674.3 \\
\hline
\end{tabular}

Note: $\alpha_{e}$ - coefficient of convective heat transfer from the refrigerant to the condenser wall, $\mathrm{W} /\left(\mathrm{m}^{2} \cdot \mathrm{K}\right) ; \alpha_{w}$ - coefficient of convective heat transfer from the condenser wall to local water, $\mathrm{W} /\left(\mathrm{m}^{2} \cdot \mathrm{K}\right) ; k$ - heat transfer coefficient, $\left.\mathrm{W} /\left(\mathrm{m}^{2} \cdot \mathrm{K}\right)\right)$

Table 3

Permanently hour the performance of the mathematical model of the dynamics of the temperature of the water

\begin{tabular}{|l|c|c|c|c|c|c|c|c|}
\hline $\begin{array}{c}\text { Levels of } \\
\text { operation }\end{array}$ & $T_{W \prime} \mathrm{s}$ & $T_{\mathrm{m} \prime} \mathrm{s}$ & $L_{W \prime} \mathrm{m}$ & $\varepsilon$ & $L_{e \prime} \mathrm{m}$ & $L_{e}^{*}$ & $\varepsilon^{*}$ & $\zeta$ \\
\hline first level & 6.23 & 2.62 & 24.61 & 1.7756 & 2.50 & 0.2857 & 1.2683 & 0.6811 \\
\hline second level & 5.42 & 2.28 & 21.43 & 1.6014 & 2.48 & 0.2874 & 1.1412 & 0.6309 \\
\hline third level & 4.54 & 1.91 & 17.95 & 1.4182 & 2.44 & 0.2907 & 1.0059 & 0.5945 \\
\hline fourth level & 3.56 & 1.50 & 14.08 & 1.2204 & 2.30 & 0.3030 & 0.8506 & 0.5794 \\
\hline
\end{tabular}

Note: $T_{W,} T_{m}$ - time constants characterizing the thermal storage capacity of local water, metal, s; $L_{w 1} L_{\varepsilon,} L_{\theta}^{*}, \varepsilon, \varepsilon^{*}, \zeta$ - coefficients of the mathematical model of the local water temperature dynamics 
Presented in Table 3 time constants and coefficients that are part of the mathematical model of dynamics (3) are obtained on the basis of heat transfer parameters as part of complex mathematical modeling (Table 2)

\section{Research results}

A complex integrated system for supporting the functioning of heat pump power supply has been developed (Table 4). This system is based on predicted local water temperature changes. The voltage at the input to the grid inverter, the voltage at the output from the frequency converter and the voltage frequency are continuously measured. Advance decisions are made to change the power of the heat pump compressor electric motor in accordance with the change in the thermal power of the lower section of the two-section storage tank as a lowpotential energy source.

The local water temperature at the outlet of the heat pump condenser is determined as follows:

$$
t_{w i+1}(\tau)=t_{w i}+\left(\left(\frac{\Delta t_{w i+1}(\tau)}{\Delta t_{c . c . n .}(\tau)}-\frac{\Delta t_{w i}(\tau)}{\Delta t_{c . c . n .}(\tau)}\right)\left(t_{w 22}-t_{w 1}\right)\right),
$$

where $t_{w}$ - temperature of local water, ${ }^{\circ} \mathrm{C} ; t_{1}, t_{2}-$ initial and final value of local water temperature, ${ }^{\circ} \mathrm{C}$, respectively; $i-$ the number of levels of functioning; $\tau$ - time, s. Index c. c. n. constant, calculated value of the parameter of the lower level of functioning.

So, for example, in the period of time $94.5 \cdot 10^{5} \mathrm{~s}(2625 \mathrm{~h})$ from the beginning of the heating season, the temperature of local water using formula (15) is:

$$
45.51{ }^{\circ} \mathrm{C}=45.51{ }^{\circ} \mathrm{C}+(0.4783-0.4752)\left(55^{\circ} \mathrm{C}-35^{\circ} \mathrm{C}\right) \text {. }
$$

During this period of time, when the voltage at the input to the grid inverter changes to a level of $193.6 \mathrm{~V}$, predicting an increase in the electric grid charge, it is necessary to increase the power of the heat pump compressor electric motor based on the voltage frequency change to $31.78 \mathrm{~Hz}$. Adopting a proactive decision to increase the number of revolutions of the compressor electric motor allows increasing the refrigerant consumption to the level of $0.035 \mathrm{~kg} / \mathrm{s}$ and ensuring the maintenance of the local water temperature at $45.51{ }^{\circ} \mathrm{C}$. The implementation of such actions will allow, while maintaining the functioning of the heat pump power supply, to coordinate the production and consumption of energy.

Local water temperature change support

\begin{tabular}{|c|c|c|c|}
\hline Time, $\tau, 10^{5} \mathrm{~s}$ & Changing the parameters of the technological process & $\Delta t_{W}(\tau) / \Delta t_{\text {c...n. }}(\tau)$ & $t_{w}(\tau),{ }^{\circ}[$ \\
\hline 0 & $\begin{array}{c}\text { Charge } \\
U_{1}=84 \mathrm{~V} ; U_{2}=190.7 \mathrm{~V} ; t=25.09 \mathrm{~Hz} ; G_{x}=0.0340 \mathrm{~kg} / \mathrm{s} ; t_{x \text { in }}=45^{\circ}{ }^{\circ} ; t_{x \text { out. }}=40.5^{\circ} \mathrm{C} ; \\
t_{w \text { in }}=35{ }^{\circ}{ }^{\circ} ; t_{W \text { out. }}=40^{\circ} \mathrm{C}\end{array}$ & 1 & 35 \\
\hline 10.5 & $t_{x \text { in }}=45^{\circ} C_{;} ; t_{x \text { out. }}=40.5^{\circ} \mathrm{C} ; t_{\mathrm{w} \text { in }}=35^{\circ} \mathrm{C} ; t_{\mathrm{w} \text { out. }}=40^{\circ} \mathrm{C} ; U_{1}=90 \mathrm{~V} ; U_{2}=190.7 \mathrm{~V}$ & 0.9438 & 36.12 \\
\hline 21 & $t_{x \text { in }}=45^{\circ} \mathrm{C} ; t_{x \text { out. }}=40.5^{\circ} \mathrm{C} ; t_{\mathrm{w} \text { in }}=35^{\circ} \mathrm{C} ; t_{\mathrm{w} \text { out. }}=40{ }^{\circ} \mathrm{C} ; U_{1}=96 \mathrm{~V} ; U_{2}=190.7 \mathrm{~V}$ & 0.8875 & 37.25 \\
\hline 31.5 & $t_{x \text { in }}=45^{\circ} \mathrm{C} ; t_{x \text { out. }}=40.5^{\circ} \mathrm{C} ; t_{w \text { in }}=35^{\circ} \mathrm{C} ; t_{w \text { out. }}=40{ }^{\circ} \mathrm{C} ; U_{1}=108 \mathrm{~V} ; U_{2}=190.7 \mathrm{~V}$ & 0.7751 & 39.5 \\
\hline 42 & $t_{x \text { in }}=45^{\circ} \mathrm{C} ; t_{x \text { out. }}=40.5^{\circ} \mathrm{C} ; t_{W \text { in }}=35^{\circ} \mathrm{C} ; t_{W \text { out. }}=40^{\circ} \mathrm{C} ; U_{1}=114 \mathrm{~V} ; U_{2}=190.7 \mathrm{~V}$ & 0.7188 & 40.63 \\
\hline 52.5 & $t_{x \text { in }}=45^{\circ} \mathrm{C} ; t_{x \text { out. }}=40.5^{\circ} \mathrm{C} ; t_{W \text { in }}=35^{\circ} \mathrm{C} ; t_{W \text { out. }}=40^{\circ} \mathrm{C} ; U_{1}=126 \mathrm{~V} ; U_{2}=190.7 \mathrm{~V}$ & 0.6064 & 42.88 \\
\hline 63 & $t_{x \text { in }}=45^{\circ} \mathrm{C} ; t_{x \text { out. }}=40.5^{\circ} \mathrm{C} ; t_{\mathrm{w} \text { in }}=35^{\circ} \mathrm{C} ; t_{\mathrm{w} \text { out. }}=40^{\circ} \mathrm{C} ; U_{1}=130 \mathrm{~V} ; U_{2}=190.7 \mathrm{~V}$ & 0.5689 & 43.63 \\
\hline 73.5 & $t_{x \text { in }}=45^{\circ} \mathrm{C} ; t_{x \text { out. }}=40.5^{\circ} \mathrm{C} ; t_{W \text { in }}=35^{\circ} \mathrm{C} ; t_{W \text { out. }}=40^{\circ} \mathrm{C} ; U_{1}=136 \mathrm{~V} ; U_{2}=190.7 \mathrm{~V}$ & 0.5126 & 44.76 \\
\hline 84 & $t_{x \text { in }}=45^{\circ} \mathrm{C} ; t_{x \text { out }} 40.5^{\circ} \mathrm{C} ; t_{w \text { in }}=35^{\circ} \mathrm{C} ; t_{w \text { out. }}=40^{\circ} \mathrm{C} ; U_{1}=140 \mathrm{~V} ; U_{2}=190.7 \mathrm{~V}$ & 0.4752 & 45.51 \\
\hline 94.5 & 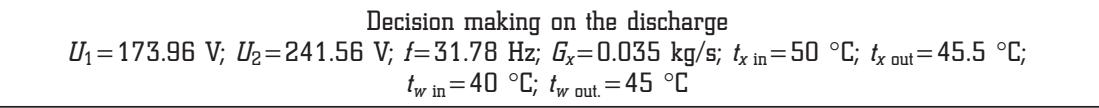 & 0.4783 & 45.51 \\
\hline 105 & 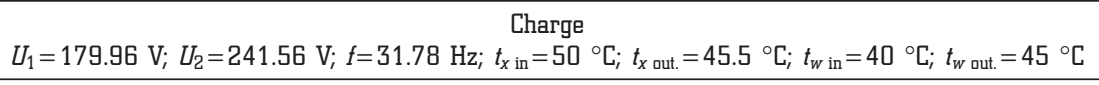 & 0.4355 & 46.37 \\
\hline 115.5 & $t_{x \text { in }}=50{ }^{\circ} \mathrm{C} ; t_{x \text { out. }}=45.5^{\circ} \mathrm{C} ; t_{\mathrm{w} \text { in }}=40^{\circ} \mathrm{C} ; t_{\mathrm{w} \text { out. }}=45^{\circ} \mathrm{C} ; U_{1}=185.96 \mathrm{~V} ; U_{2}=241.56 \mathrm{~V}$ & 0.3931 & 47.22 \\
\hline 126 & $t_{x \text { in }}=50{ }^{\circ} \mathrm{C} ; t_{x \text { uut. }}=45.5^{\circ} \mathrm{C} ; t_{\mathrm{w} \text { in }}=40^{\circ} \mathrm{C} ; t_{\mathrm{w} \text { out. }}=45^{\circ} \mathrm{C} ; U_{1}=191.96 \mathrm{~V} ; U_{2}=241.56 \mathrm{~V}$ & 0.3506 & 48.07 \\
\hline 136.5 & $t_{x \text { in }}=50{ }^{\circ} \mathrm{C} ; t_{x \text { out. }}=45.5^{\circ} \mathrm{C} ; t_{w \text { in }}=40{ }^{\circ} \mathrm{C} ; t_{w \text { out. }}=45{ }^{\circ} \mathrm{C} ; U_{1}=197.96 \mathrm{~V} ; U_{2}=241.56 \mathrm{~V}$ & 0.3082 & 48.92 \\
\hline 147 & $\begin{array}{l}\text { Decision making on the discharge } \\
U_{1}=257.9 \mathrm{~V} ; U_{2}=310.17 \mathrm{~V} ; f=40.81 \mathrm{~Hz} ; G_{x}=0.0357 \mathrm{~kg} / \mathrm{s} ; t_{x \text { in }}=55^{\circ} \mathrm{C} ; t_{x \text { out. }}=50.5^{\circ} \mathrm{C} ; \\
t_{w \text { in }}=45{ }^{\circ} \mathrm{C} ; t_{W \text { out. }}=50{ }^{\circ} \mathrm{C}\end{array}$ & 0.3125 & 49 \\
\hline 157.5 & 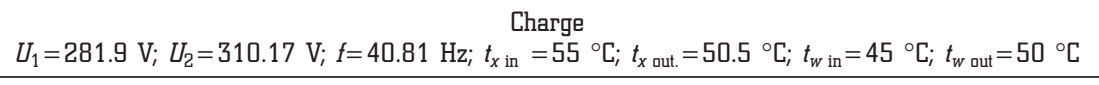 & 0.1690 & 51.87 \\
\hline 161.6 & $\begin{array}{l}\text { Decision making on the discharge } \\
U_{1}=341.93 \mathrm{~V} ; U_{2}=380 \mathrm{~V} ; f=50 \mathrm{~Hz} ; G_{x}=0.0363 \mathrm{~kg} / \mathrm{s} ; t_{x} \text { in }=60{ }^{\circ} \mathrm{C} ; t_{x} \text { out. }=55.5^{\circ} \mathrm{C} ; \\
t_{w \text { in }}=50{ }^{\circ}{ }^{\circ} ; t_{w \text { out. }}=55^{\circ} \mathrm{C}\end{array}$ & 0.0690 & 53.67 \\
\hline 161.6 & $\begin{array}{c}\text { Discharge } \\
U_{1}=341.93 \mathrm{~V} ; U_{2}=380 \mathrm{~V} ; t=50 \mathrm{~Hz} ; G_{x}=0.0363 \mathrm{~kg} / \mathrm{s} ; t_{x \text { in }}=60{ }^{\circ} \mathrm{C} ; t_{x \text { out. }}=55.5^{\circ} \mathrm{C} ; \\
t_{\mathrm{w} \text { in }}=500^{\circ} \mathrm{C} ; t_{\mathrm{w} \text { out }}=55^{\circ} \mathrm{C}\end{array}$ & 0 & 55 \\
\hline
\end{tabular}

Table 4

Note: $t_{\mathrm{x} \text { in }} t_{\mathrm{x} \text { out }} t_{\mathrm{w} \text { in }} t_{w \text { out }}$ - coolant temperature, local water temperature at the inlet to the condenser, at the outlet from the condenser, ${ }^{\circ} \mathrm{C}$ $G_{x}$ - refrigerant consumption, $\mathrm{kg} / \mathrm{s} ; f$ - voltage frequency, $\mathrm{Hz} ; U_{1}, U_{2}$ - voltage at the input to the network inverter and at the output from the frequency converter, $V_{i} \tau$ - time, s. Indexes: $w$ - internal flow - local water; c.c.n. - constant, calculated value of the parameter of the lower level of functioning 


\section{SWOT analysis of research results}

Strengths. It is proposed to measure the voltage at the input to the grid inverter from hybrid solar collectors and the voltage at the output from the frequency converter when measuring the voltage frequency. The voltage ratio is measured, it is included in the $K_{u}$ coefficient according to the analytical determination of the local water temperature using the transfer function: «local water temperature - refrigerant consumption». So, predicting an increase in the charge of the electrical network, it is necessary to take a proactive decision to increase the power of the electric motor of the heat pump compressor based on the change in the voltage frequency. This will make it possible, by supporting the functioning of the heat pump power supply, to harmonize the production and consumption of energy.

Weaknesses. Additional capital investments in heat pump power supply will be required, but they will pay off $25-30 \%$ earlier due to advanced decisions than when using local water temperature measurement.

Opportunities. It is proposed to coordinate the frequency control of the electric motor power of the heat pump compressor and the change in the thermal power of the lowpotential energy source. The use of the lower section of a two-section storage tank connected to hybrid solar collectors makes it possible to reduce the cost of heat production, the payback period of the heat pump system, and increase the monetary savings in electricity consumption by up to $30 \%$.

Threats. The power system can set the ratio of production and consumption of electrical energy. The coordination of production and consumption requires joining the Smart Grid technologies to prevent the peak load of the power system under voltage regulation conditions when connecting the heat pump power supply.

\section{Conclusions}

1. The establishment of the ratio of voltage at the input to the grid inverter from hybrid solar collectors to the voltage at the output of the frequency converter when measuring the voltage frequency is provided. This makes it possible to biasedly influence the change in the temperature of the local water.

2. A comprehensive mathematical modeling of the heat pump system for the established levels of functioning has been completed. Determination of the operating parameters of the heat pump system, the parameters of heat transfer in the condenser, time constants and coefficients of the mathematical model of the local temperature dynamics is based on an integrated system for maintaining the charge of the lower section of the storage tank. Coordination with a change in the thermal power of a low-potential energy source - the lower section of a two-section storage tank connected to hybrid solar collectors.

3. It is proposed to predict changes in the temperature of local water with continuous measurement of the voltage at the input to the grid inverter from hybrid solar collectors, the voltage at the output from the frequency converter and the voltage frequency. An integrated system for supporting the functioning of heat pump power supply is based on making proactive decisions to change the refrigerant consumption. Frequency control of the heat pump power supply allows making advanced decisions on changing the refrigerant flow rate and on changing the voltage frequency by changing the number of revolutions of the heat pump compressor electric motor.

\section{References}

1. Bondarchuk, A. (2019). Study into predicted efficiency of the application of hybrid solar collectors to supply energy to multiapartment buildings. Eastern-European Journal of Enterprise Technologies, 4 (8 (100)), 69-77. doi: http://doi.org/10.15587/17294061.2019.174502

2. Shahriari, M., Blumsack, S. (2018). The capacity value of optimal wind and solar portfolios. Energy, 148, 992-1005. doi: http:// doi.org/10.1016/j.energy.2017.12.121

3. Li, Y., Yang, W., He, P., Chen, C., Wang, X. (2019). Design and management of a distributed hybrid energy system through smart contract and blockchain. Applied Energy, 248, 390-405. doi: http://doi.org/10.1016/j.apenergy.2019.04.132

4. Saad, A. A., Faddel, S., Mohammed, O. (2019). A secured distributed control system for future interconnected smart grids. Applied Energy, 243, 57-70. doi: http://doi.org/10.1016/j.apenergy.2019.03.185

5. Perera, A. T. D., Nik, V. M., Wickramasinghe, P. U., Scartezzini, J.-L. (2019). Redefining energy system flexibility for distributed energy system design. Applied Energy, 253, 113572. doi: http://doi.org/10.1016/j.apenergy.2019.113572

6. Mak, D., Choeum, D., Choi, D.-H. (2020). Sensitivity analysis of volt-VAR optimization to data changes in distribution networks with distributed energy resources. Applied Energy, 261, 114331. doi: http://doi.org/10.1016/j.apenergy.2019.114331

7. Xiqiao, L., Yukun, L., Xianhong, B. (2019). Smart grid service evaluation system. Procedia CIRP, 83, 440-444. doi: http:// doi.org/10.1016/j.procir.2019.04.138

8. Chaikovskaya, E. (2017). Development of energy-saving technology to support functioning of the lead-acid batteries. EasternEuropean Journal of Enterprise Technologies, 4 (8 (88)), 56-64. doi: http://doi.org/10.15587/1729-4061.2017.108578

9. Chaikovskaya, E. (2019). Development of energy-saving technology to maintain the functioning of a wind-solar electrical system. Eastern-European Journal of Enterprise Technologies, 4 (8 (100)), 57-68. doi: http://doi.org/10.15587/1729-4061.2019.174099

10. Dincer, I., Rosen, M. A., Ahmadi, P. (2017). Modeling and Optimization of Heat Pump Systems. Optimization of Energy Systems, 183-198. doi: http://doi.org/10.1002/9781118894484.ch6

11. Underwood, C. P. (2016). Heat pump modelling. Advances in Ground-Source Heat Pump Systems, 387-421. doi: http://doi.org/ 10.1016/b978-0-08-100311-4.00014-5

12. Li, Y., Yu, J. (2016). Theoretical analysis on optimal configurations of heat exchanger and compressor in a two-stage compression air source heat pump system. Applied Thermal Engineering, 96, 682689. doi: http://doi.org/10.1016/j.applthermaleng.2015.11.132

13. Matuska, T., Sourek, B., Sedlar, J. (2016). Heat Pump System Performance with PV System Adapted Control. Proceedings of EuroSun2016. doi: http://doi.org/10.18086/eurosun.2016.08.06

14. Yan, G., Bai, T., Yu, J. (2016). Energy and exergy efficiency analysis of solar driven ejector-compressor heat pump cycle. Solar Energy, 125, 243-255. doi: http://doi.org/10.1016/j.solener.2015.12.021

15. Van Leeuwen, R. P., Gebhardt, I., de Wit, J. B., Smit, G. J. M. (2016). A Predictive Model for Smart Control of a Domestic Heat Pump and Thermal Storage. Proceedings of the 5th International Conference on Smart Cities and Green ICT Systems. doi: http://doi.org/10.5220/0005762201360145

16. Chaikovskaya, E. (2020). Development of Smart Grid technology for maintaining the functioning of a biogas cogeneration system. Eastern-European Journal of Enterprise Technologies, 3 (8 (105)), 56-68. doi: http://doi.org/10.15587/1729-4061.2020.205123

17. Jiang, S. (2017). Air-Source Heat Pump Systems. Handbook of Energy Systems in Green Buildings, 1-44. doi: http://doi.org/ 10.1007/978-3-662-49088-4 2-1

18. Rees, S. J. (2016). An introduction to ground-source heat pump technology. Advances in Ground-Source Heat Pump Systems, 1-25. doi: http://doi.org/10.1016/b978-0-08-100311-4.00001-7

19. Suzuki, M., Yoneyama, K., Amemiya, S., Oe, M. (2016). Development of a Spiral Type Heat Exchanger for Ground Source Heat Pump System. Energy Procedia, 96, 503-510. doi: http:// doi.org/10.1016/j.egypro.2016.09.091

20. Chaikovskaya, E. (2018). Development of energy-saving technology for maintaining the functioning of heat pump power supply. Eastern-European Journal of Enterprise Technologies, 4 (8 (94)), 13-24. doi: http://doi.org/10.15587/1729-4061.2018.139473

Chaikovskaya Eugene, PhD, Senior Researcher, Associate Professor, Department of Theoretical, General and Alternative Energy, Odessa National Polytechnic University, Odesa, Ukraine, ORCID: http:// orcid.org/0000-0002-5663-2707, e-mail: eechaikovskaya@gmail.com 